\title{
ANALISIS PERBANDINGAN PELAT LANTAI KONVENSIONAL DAN PRACETAK DITINJAU DARI ASPEK BIAYA DAN WAKTU PADA DERMAGA 006 TERMINAL OPERASI 1 PELABUHAN TANJUNG PRIOK, JAKARTA UTARA
}

\author{
(Comparative Analysis of Conventional Floor Plates and Prefabricated Plates \\ Aspects of Cost and Time at Pier 006 Operating Terminal 1 Tanjung Priok Port, North Jakarta)
}

\author{
Joryans Syamsuddin ${ }^{1}$, Niken Warastuti $^{1}$, Resti Nur Arini $^{1}$ \\ ${ }^{1}$ Program Studi Teknik Sipil Universitas Pancasila \\ E-mail: joryansyam@gmail.com
}

\begin{abstract}
ABSTRAK
Pelabuhan Tanjung Priok merupakan pelabuhan kelas utama dilingkungan PT. Pelabuhan Indonesia II (Persero). Sebagai pelabuhan terbesar di Indonesia diperlukan fasilitas alat bongkar muat yang dapat mendukung kegiatan operasional berjalan optimal. Agar alat bongkar muat dengan \pm 100 ton dapat beroperasi di atas dermaga maka perlu diadakan pekerjaan perkuatan dan peninggian dermaga, sehingga dapat melayani kapal dengan draft yang lebih dalam. Oleh karena itu PT. Pelabuhan Indonesia II (Persero) Cabang Tanjung Priok akan melakukan pekerjaan perkuatan dan peninggian dermaga dan lapangan di Dermaga 005, 006 dan 007 Terminal Operasi 1 Pelabuhan Tanjung Priok. Pada proyek ini dalam hal pekerjaan pelat lantai digunakan sistem konvensional. Dan tujuan penelitian ini adalah melakukan komparasi pada sebuah proyek dengan menggunakan kedua metode pelat lantai konvensional dan pracetak agar efisien dalam penerapan sistem, biaya dan waktu. Dari studi yang didapat untuk pekerjaan pelat lantai dengan metode konvensional dan precast didapat efisiensi biaya sebesar 15,308,130.00 atau 29.82\% dan mendapatkan efisiensi waktu selama 7 minggu dengan metode precast.
\end{abstract}

Kata Kunci : Precast, Pelat Lantai, Biaya, Waktu.

\begin{abstract}
The Port of Tanjung Priok is a major class port within PT. Pelabuhan Indonesia II (Persero). As the largest port in Indonesia required facilities unloading equipment that can be used for operational activities running optimally. In order to unloading tools with \pm 100 tons can be used in places needed for better and better jobs, you can use deeper vessels. Therefore PT. Pelabuhan Indonesia II (Persero) Tanjung Priok Branch will perform strengthening and docking and field elevation work at Docks 005, 006 and 007 Terminal of Operation 1 of Tanjung Priok Port. At the moment it is used conventional.And the purpose of this research is to conduct research by using method and efficiency. From the study obtained for floor plate work with conventional and precast methods, the cost was 15,308,130,00 or 29,82\% and got save for 7 weeks with precast method.
\end{abstract}

Keywords : Precast, Floor Plates, Costs, Time. 


\section{PENDAHULUAN}

Di masa ini metode pekerjaan struktur atas seperti balok, kolom dan pelat lantai lebih dikembangkan agar waktu dapat dikendalikan dengan tepat. Salah satu metode konstruksi yang dikembangkan agar menghasilkan efisiensi waktu dalam pekerjaan konstruksi adalah sistem struktur beton pracetak. Beton pracetak banyak digunakan sebagai alternatif pengganti sistem beton konvensional.

PT. Pelabuhan Indonesia II (Persero) Cabang Tanjung Priok akan melakukan pekerjaan perkuatan, peninggian dermaga dan lapangan di Dermaga 005, 006 dan 007 Terminal Operasi 1 Pelabuhan Tanjung Priok. Pada awal perencanaan proyek ini direncanakan untuk menggunakan metode pekerjaan pelat lantai sistem konvensional tetapi pada saat pelaksanaan mengalami keterlambatan dalam pekerjaan proyek di dermaga 007. Maka dilakukan inovasi dengan menggunakan pelat lantai pracetak half slab untuk mempercepat pelaksanaan proyek dermaga 007. Pada saat dermaga 007 melakukan pengecoran topping pelat lantai pracetak half slab, kontraktor mengganti metode pelat lantai menggunakan konvensional yang dikarenakan produksi pelat lantai pracetak half slab mengalami keterlambatan.

Maka pada penelitian ini dilakukan komparasi biaya dan waktu pada proyek dermaga 006 PT. Pelabuhan Indonesia II (Persero) Cabang Tanjung Priok dengan menggunakan kedua metode pelat lantai pracetak half slab dan pracetak agar efisien dalam penerapan sistem.

\section{METODE}

Berdasarkan latar belakang diatas maka dapat dibuat identifikasi masalah sebagai berikut:

1. Produktivitas tenaga kerja dalam pelaksanaan proses konstruksi pada pelat lantai dermaga 006 dalam memilih metode beton precast atau beton konvensional.

2. Biaya dan waktu pelaksanaan yang dibutuhkan dalam penyelesain pekerjaan pada penggunaan material beton precast atau konvensional.

3. Pemilihan material yang tepat guna dan tepat biaya untuk pelaksanaan penyelesaian proses konstruksi.

Berdasarkan identifikasi masalah, dapat dibuat suatu perumusan masalah yaitu dengan mencari metode yang tepat digunakan dalam pekerjaan pelat lantai dermaga 006, kemudian mencari berapa total kebutuhan biaya pelaksanaan dari metode pelaksanaan pekerjaan pelat lantai dermaga 006, serta material yang lebih efisien dan efektif digunakan, mencari selisih biaya dan waktu pelaksanaan yang ditimbulkan dari metode tersebut. Sehingga dapat dianalisa berupa perbandingan antara sistem pelat lantai konvensional dan pracetak beton yang ditinjau dari segi biaya dan waktu. Dari hasil analisa akan diperoleh perbandingan biaya dan waktu antara sistem pelat lantai konvensional dan pracetak beton sebagai rekomendasi kepada kontraktor untuk memilih metode yang tepat dan efisien.

\section{Perbandingan Sistem Konvensional dengan Pracetak}

Secara desain pracetak Membutuhkan wawasan yang luas terutama yang ada kaitannya dengan fabrikasi sistem, transportasi serta pelaksanaan atau pemasangan komponen, system sambungan dan sebagainya. Tetapi konvensional sangat sederhana.

\section{Tahap Pelaksanaan Pracetak}

Menurut Ervianto (2006) , tahap pelaksanaan beton pracetak dijelaskan mulai dari tahap pembuatan sampai dengan tahap overtoping antara lain sebagai berikut :

A. Tahap Produksi atau Pabrikasi

Pada tahap produksi atau pabrikasi ini dilakukan di area lapangan, yang jadwal pembuatannya berjalan sendiri, jadi tidak mengganggu jadwal inti. Area pembuatan/pabrikasi ini nantinya bersebelahan dengan area penumpukan.

B. Tahap Pengiriman

Pada tahap pengiriman material pracetak ini sangat diperlukan koordinasi antara pihak kontraktor dan suplier pracetak. Pihak suplier mengirim material setelah ada instruksi dari kontraktor, karena hal tersebut sangat berkaitan dengan metode pelaksanaan di lapangan. Jumlah elemen pracetak mengenai bentuk dan ukuran sesuai dengan konfirmasi pihak kontraktor.

C. Tahap Penumpukan

Beberapa alasan sebagai penyebab dilakukan penumpukan material Pracetak:

a. Jumlah beton prcast yang akan dipasang sangat banyak, sehingga tidak memungkinkan untuk pemasangan pelat secara langsung dari trailer ke titik pelat rencana.

b. Lokasi proyek cukup luas, sehingga tersedia tempat penumpukan pelat dimana tempat ini diusahakan tidak mengganggu aktivitas proyek.

D. Tahap Pemasangan dan Pengangkatan

Pada tahap pemasangan beton Pracetak harus direncanakan sematang mungkin, baik dari segi peralatan, pekerja, dan siklus pemasangannya.

E. Titik Angkat dan Sokongan

Menurut PCl Design Handbook (2004) Dalam pemasangan pelat pracetak harus pula diingat bahwa pelat akan mengalami pengangakatan sehingga perlu direncanakan tulangan angkat untuk pelat.

F. Tahap Penyambungan

Menurut Ervianto (2006) cara penyambungan yang dapat dilakukan dibedakan menjadi dua yaitu sambungan basah dan sambungan kering.

G. Tahap Pengecoran

Pengecoran over topping dilakukan setelah pemasangan pembesian wire mesh dilakukan. Kebutuhan baja tulangan pada toping dalam menampung gaya geser horizontal direncanakan dengan menggunakan geser friksi (shear friction concept). 


\section{Analisis Biaya}

Menurut Sastraatmaja (2006), Analisis biaya dilakukan untuk memperoleh perkiraan biaya pelaksanaan suatu pekerjaan dengan berdasarkan sumber daya yang ada dan metode pelaksanaan te harus mengetahui spesifikasi yang digunakan dalam perencanaan konstruksi tersebut. Misalnya untuk volume menggunakan satuan $\mathrm{m}^{3}$ (meter kubik). Sedangkan untuk berat menggunakan satuan $\mathrm{kg}$.

A. Komponen biaya langsung (direct cost)

Direct Cost adalah biaya yang mudah ditelusuri ke cost object. Bila cost object-nya suatu produk, sebagai contoh adalah meja tulis, maka kayu merupakan direct cost terhadap cost object meja tulis karena kayu dengan mudah dapat ditelusuri pemakaiannya ke meja. Dengan kata lain dapat dengan mudah dihitung berapa kebutuhan meja akan kayu.

B. Komponen biaya tak langsung (indirect cost)

Indirect cost adalah biaya yang tidak mudah ditelusuri ke cost object sekalipun dapat ditelusuri tapi dengan cara yang tidak ekonomis. Bila cost object-nya meja maka biaya listrik yang dipakai untuk penerangan merupakan indirect cost terhadap cost.

Adapun langkah-langkah yang akan dilakukan tentang perbandingan sistem pelat lantai konvensional dan Pracetak half slab yang dijadikan kerangka acuan. langkah-langkah dalam penelitian ini dapat dilihat pada Gambar 1.

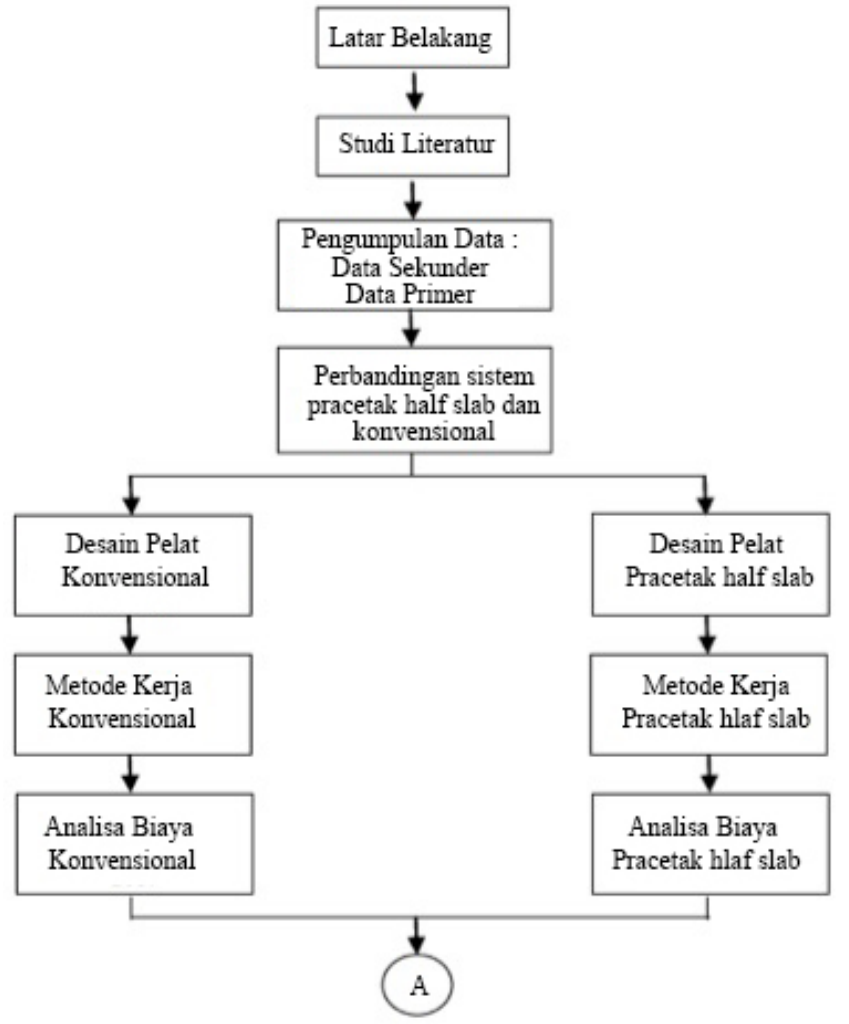

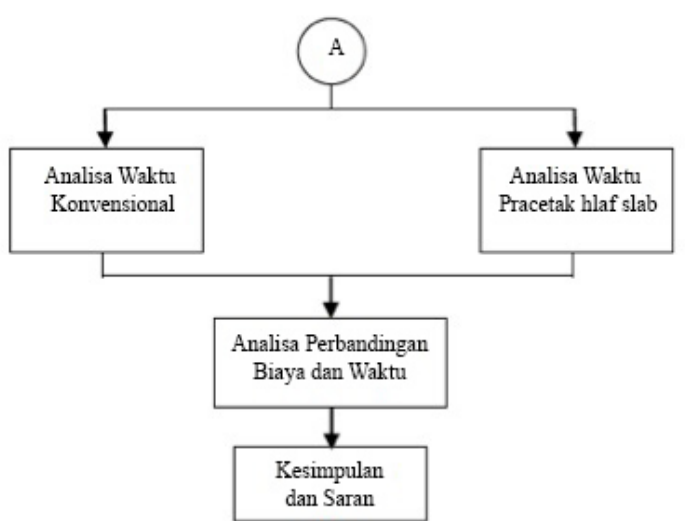

Gambar 1. Diagram alir Penelitian

\section{ANALISA DATA}

Pengumpulan data dilakukan berupa data primer dan sekunder. Data sekunder merupakan yang diperoleh dari pihak pelaksana. Adapun data primer didapat dari observasi pengambilan data waktu pekerjaan menggunakan stop watch, video kamera, wawancara dengan pekerja atau pun engineer, dan dari buku atau literature yang sudah ada dasar penelitiannya. Data sekunder digunakan sebagai data acuan dari besarnya biaya pelat konvensional dan pracetak half slab, sedangkan data primer bisa dipakai sebagai acuan waktu pelaksanaan konvensional. Objek yang dijadikan lokasi penelitian tugas akhir adalah pekerjaan perkuatan dan peninggian dermaga dan lapangan di Dermaga 005, 006 dan 007 Terminal Operasi 1 Pelabuhan Tanjung Priok. Dan penelitian ini khusus untuk Dermaga 006 Terminal Operasi 1 Pelabuhan Tanjung Priok.

Data Umum Proyek

Lokasi proyek Peninggian Dermaga dan lapangan $\begin{array}{lll}\text { penumpukan } & 005,006 & \text { dan } \\ \end{array}$ ini berada di Jl. Nusantara II Pelabuhan Tanjung Priok, Jakarta Utara DKI Jakarta. Proyek Peninggian Dermaga dan lapangan penumpukan 005,006 dan 007 dengan panjang lapangan $493 \mathrm{~m}$ dan panjang dermaga $556,8 \mathrm{~m}$ dan terdiri dari 4 bagian konstruksi yaitu:

1. Konstruksi King Pile dan Soldier Pile

2. Konstruksi Tiang Pancang

3. Konstruksi Lantai Beton

4. Konstruksi Lapangan Penumpukan

Proyek Peningkatan Dermaga dan Lapangan Penumpukan 005,006 dan 007 di sebelah utara berbatasan dengan dermaga 007 sisi utara, di sebelah timur berbatasan dengan Kolam 1, di sebelah selatan berbatasan dengan lap. 005 Selatan, dan disebelah barat berbatasan dengan jalan nusantara II Pelabuhan Tanjung Priok. 


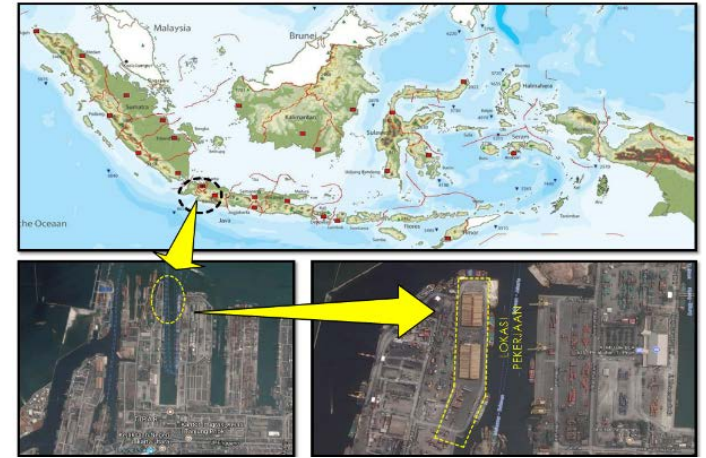

Gambar 2. Lokasi Proyek Dermaga dan lapangan 005,006 dan 007

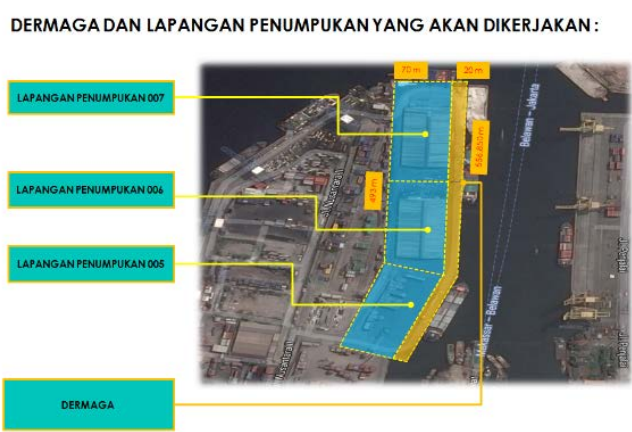

Gambar 3. Lokasi Proyek Dermaga dan lapangan 005,006 dan 007

Berikut data umum mengenai proyek ini:

$\begin{array}{lllll}\text { a.Nama Proyek } & \text { :PEKERJAAN } & & \text { PENINGKATAN } \\ & \text { DERMAGA } & \text { DAN } & \text { LAPANGAN } \\ & \text { PENUMPUKAN } & \text { 005, } 006 & \text { DAN } 007 \\ & \text { PELABUHAN } & \text { TANJUNG } & \text { PRIOK } \\ & \text { TAHUN 2017 } & & & \\ \text { b.Lokasi Proyek } & \text { :DERMAGA } & \text { DAN } & \text { LAPANGAN } \\ & \text { PENUMPUKAN } & \text { O05, 006 DAN } 007 \\ & \text { PELABUHAN TANJUNG PRIOK } & \end{array}$

c.Pemberi Tugas :PT. Pelabuhan Indonesia II ( Persero)

d.Nilai Kontrak :Rp.197.378.653.000,- (Termasuk PPN $10 \%)$

e.Waktu :420 Hari Kalender

f.Pemeliharaan :365 Hari

g.Kontraktor :PT. Nindya Karya ( Persero)

h.Konsultan MK :PT. Lapi Ganeshatama Consulting

i.Sifat Kontrak : Unit price dan Lumpsum

j.Pile yang di gunakan : - Tiang Pancang Beton Dia. 600

- King Pile \& Soldier pile Dia. 610

\section{Perbandingan Sistem Pracetak Half Slab dengan Konvensional \\ Desain Pelat}

Analisis desain pelat menjadi dasar untuk menghitung besarnya volume pekerjaan tiap lantai. Secara garis besar alur desain pelat konvensional dengan pelat Pracetak half slab sebagai berikut:

1. Desain Pelat Konvensional

Desain pelat konvensional tidak direncanakan karena penulis menggunakan data sekunder shop drawing sebagai acuan.

2. Desain Pelat Pracetak Half slab

Dimulai dari penentuan dimensi tebal pelat Pracetak,penentuan ukuran dimensi pelat Pracetak ,perencanaan tulangan pelat dan kontrol tulangan pelat pada setiap proses produksi yakni ketika belum komposit.

\section{Metode Kerja}

Menyusun secara garis besar tahapan kerja untuk metode konvensional dan metode Pracetak half slab serta menganalisis aktifitas kegiatan setiap pekerjaan. Analisis metode kerja menjadi dasar untuk menghitung biaya dan waktu pelaksanaan untuk masing-masing metode. Secara singkat penjelasan metode kerja sebagai berikut:

a. Metode Pelat Konvensional

Diawali dari pemasangan perancah/schaffolding sebagai dudukan bekisting balok dan pelat, kemudian setting ketinggian perancah sesuai dengan elevasi yang ditentukan, lalu pasang bekisting balok dan pelat secara bersamaan, kemudian dipasang tulangan balok dan pelat secara bersamaan, setelah itu dilakukan checklist apakah besi terpasang dengan benar sesuai dengan gambar shop drawing, setelah itu dilanjutkan dengan pengecoran.

b. Metode Pracetak Half slab

Diawali dari desain awal Pracetak, pembuatan Pracetak di lokasi proyek dan perawatan umur beton Pracetak selama 30 hari, pemasangan perancah dan bekisting balok, penulangan balok, pengecoran balok setengahnya sebagai dudukan Pracetak half slab, dilanjutkan pengangkatan Pracetak yang berumur 30 hari, dipasang di atas balok yang telah di cor setengahnya, lalu dipasang tulangan wiremesh atas pelat, kemudian dilakukan checklist, lalu dilanjutkan pengecoran overtoping pelat.

\section{Analisa Perhitungan Pelat Lantai Pracetak}

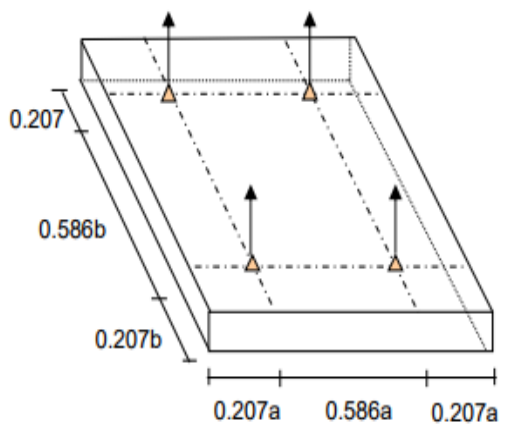

Gambar 4. Pelat lantai 
Tabel 1. Tabel Perhitungan Pelat Lantai Pracetak

\begin{tabular}{|c|l|ll|}
\hline Panjang (a) & $=$ & 5.25 & $\mathrm{~m}$ \\
\hline Lebar $(\mathrm{b})$ & $=$ & 5.25 & $\mathrm{~m}$ \\
\hline $\mathrm{ly} / \mathrm{lx}$ & $=$ & 1.000 & \\
\hline $\mathrm{fr}=0.7^{*} \sqrt{\mathrm{fc}^{\prime}}$ & $=$ & 2.876 & $\mathrm{Mpa}$ \\
\hline $\mathrm{z}$ & $=$ & 0.027 & $\mathrm{~m}^{3}$ \\
\hline $\mathrm{h}$ & $=$ & 0.175 & $\mathrm{~m}$ \\
\hline
\end{tabular}

\section{Analisa Biaya}

Analisis biaya dibutuhkan untuk mengetahui besarnya biaya yang dibutuhkan pada masing-masing metode dalam pelaksanaan proyek tersebut. Hal yang diperhatikan dalam Analisis biaya adalah:

1. Analisis Harga Satuan (AHS)

Untuk Analisis biaya pada pelat konvensional menggunakan Analisis HSPK 2017, sedangkan Analisis biaya Pracetak half slab menggunakan AHS Pracetak dari proyek lain yang menggunakan Pracetak half slab, atau juga bisa melakukan observasi di lapangan dan menghitung Analisis nya sendiri berdasarkan aturan SNI.

2. RAB

Perhitungan rencana anggaran biaya pada masing masing metode/sistem dihitung berdasarkan AHS yang berbeda. Rencana anggaran biaya dihitung berdasarkan pada volume tiap jenis pekerjaan dikalikan dengan harga satuan tiap pekerjaan.

\section{Analisa Waktu}

Analisis waktu pelaksanaan setiap kegiatan pekerjaan untuk kedua metode dihitung dengan cara membagi volume tiap pekerjaaan dari masing-masing metode dengan nilai tingkat produktivitas pekerja atau alat. Setelah itu, untuk mengetahui durasi pelaksanaan secara keseluruhan pada masing-masing metode konstruksi digunakan metode penjadwalan PDM (Precedence Diagram Methode) dengan alat bantu Microsoft Project.

\section{Tahap Perbandingan}

Aspek yang akan diAnalisis sebagai pembanding metode konvensional dengan pracetak meliputi :

1. Biaya pelaksanaan

2. Waktu pelaksanaan

Setelah didapat waktu dan biaya total yang dibutuhkan terhadap masing-masing metode yang berbeda kemudian perbedaannya dibandingkan. Kemudian akan didapat manakah metode yang dapat menghabiskan waktu lebih cepat/lama dan biaya yang lebih murah/lebih mahal.

\section{HASIL DAN PEMBAHASAN}

Perhitungan Dalam Aspek Pembiayaaan

Volume Pekerjaan Pelat Lantai Pracetak

Pelat lantai ukuran $5250 \times 5250$ mm.
Dipasang tulangan D19 - 150

1. Beton

$\mathrm{p}=5250 \mathrm{~mm}=5.25 \mathrm{~m}$

$\mathrm{I}=5250 \mathrm{~mm}=5.25 \mathrm{~m}$

tebal $=350 \mathrm{~mm}=0.35 \mathrm{~m}$

$\operatorname{Ln}=5.25-0.04=5.21$

Volume $=$ Luas penampang $\mathrm{x}$ tebal lantai $\mathrm{x}$ jumlah lantai

$=(5.25 \times 5.25) \mathrm{m} \times 0.35 \mathrm{~m} \times 90$ buah

$=868.21 \mathrm{~m}^{3}$

2. Bekisting

Keliling Penampang $=2(\mathrm{p}+\mathrm{I})$

$$
=2(5.25+5.25)
$$

$$
=20.1 \mathrm{~m}
$$

Luas Bekisting = Keliling penampang $\mathrm{x}$ tebal pelat

$$
x \text { jumlah }
$$$$
=20.1 \times 0.35 \times 90 \text { buah }
$$

$$
=633.15 \mathrm{~m}^{2}
$$

3. Tulangan

$\mathrm{D} 19-150$ arah $\mathrm{X}$ dan arah $\mathrm{Y}$

Tulangan Utama $=$ jumlah tulangan $\mathrm{x}$ berat $\mathrm{x}$ Ln

$$
\begin{aligned}
& =[(5.25 / 0.15)+1] \times[2.223 \mathrm{Kg} / \mathrm{m} \times 5.21 \mathrm{~m}] \\
& =35 \times 2.223 \mathrm{Kg} / \mathrm{m} \times 5.21 \\
& =405.36 \\
& =\text { jumlah tulangan utama } \times 4 \text { layer } \\
& =405.36 \times 4 \\
& =1621.44 \mathrm{Kg} \text { (Besi untuk } 1 \text { Pracetak) }
\end{aligned}
$$

\begin{tabular}{|c|c|c|c|c|}
\hline \multicolumn{5}{|c|}{ Bahan (PERMENPUPR 28/PRT/M/2016) } \\
\hline Koefisien & Sat & Komponen & Harga & Jumlah Harga \\
\hline 448 & $\mathrm{~kg}$ & Semen Portland & $1,460.00$ & $654,080.00$ \\
\hline 667 & $\mathrm{~kg}$ & Pasir Beton & 230.71 & $153,886.43$ \\
\hline 1000 & $\mathrm{~kg}$ & Kerikil & 100.00 & $100,000.00$ \\
\hline 2100 & Ite & Air & 100.00 & $210,000.00$ \\
\hline \multicolumn{4}{|r|}{ Total } & $1,117,966.43$ \\
\hline \multicolumn{5}{|c|}{ Upah (PERMENPUPR 28/PRT/M/2016) } \\
\hline Koefisien & Sat & Kompenen & Harga & Jumlah Harga \\
\hline 2.1 & On & Pekeria & $150,000.00$ & $315,000.00$ \\
\hline 0.35 & On & Jukang Batu & $170,000.00$ & $59,500.00$ \\
\hline 0.035 & Oh & Kepala Tukang & $190,000.00$ & $6,650.00$ \\
\hline 0.105 & Oh & Mander & $200,000.00$ & $21,000.00$ \\
\hline \multicolumn{4}{|r|}{ Total } & $402,150.00$ \\
\hline \multicolumn{4}{|c|}{ Total Upah dan Bahan } & $1,520,116.43$ \\
\hline
\end{tabular}

Total jumlah besi $=$ jumlah besi $\times$ jumlah Pracetak $=1621.44 \mathrm{Kg} \times 90$ buah

$=145929.6 \mathrm{Kg}$ ( Besi untuk 90 Pracetak)

\section{Analisa Kombinasi Harga Satuan Pekerjaan Sistem} Pracetak Half slab

1. Produksi $1 \mathrm{~m}^{3}$ beton Fc $37.5 \mathrm{Mpa}$ Slump ( $12 \pm 2$ ) $\mathrm{cm}$ Pracetak Half slab

Tabel 2. Harga Satuan Produksi Membuat $1 \mathrm{~m}^{3}$ beton Fc 37.5 Mpa Slump ( $12 \pm 2$ ) cm

2. Pembesian $1 \mathrm{~kg}$ dengan Besi Polos atau Ulir Tabel 3. Harga Satuan Produksi Pembesian $1 \mathrm{~kg}$ dengan Besi Polos atau Ulir

\begin{tabular}{|c|c|c|r|r|}
\hline Bahan (PERMENPUPR 28/PRT/M/2016) \\
\hline Koefisien & Sat & Komponen & \multicolumn{1}{|c|}{ Harga } & \multicolumn{1}{|c|}{ Jumlah Harga } \\
\hline 1.05 & kq & Besi Beton & $9,011.00$ & $9,461.55$ \\
\hline 0.015 & kq & Kawat beton & $22,500.00$ & 337.50 \\
\hline Total & & $9,799.05$ \\
\hline
\end{tabular}




\begin{tabular}{|c|c|c|c|c|}
\hline \multicolumn{5}{|c|}{ Upah (PERMENPUPR 28/PRT/M/2016) } \\
\hline Koefisien & Sat & Komponen & Harga & Jumlah Harga \\
\hline 0.007 & On & Pekeria & $150,000.00$ & $1,050.00$ \\
\hline 0.007 & Oh & Jukang Besi & $170,000.00$ & $1,190.00$ \\
\hline 0.0007 & Oh & Kenala Tukang & $190,000.00$ & 133.00 \\
\hline 0.0004 & Oh & Mander & $200,000.00$ & 80.00 \\
\hline \multicolumn{4}{|l|}{ Total } & $2,453.00$ \\
\hline \multicolumn{4}{|c|}{ Total Upah dan Bahan } & $12,252.05$ \\
\hline
\end{tabular}

3. Membuat $1 \mathrm{~m}^{2}$ Bekisting untuk Pelat Beton Pracetak ( 5 kali pakai )

Tabel 4. Harga Satuan Membuat $1 \mathrm{~m}^{2}$ Bekisting Pelat

Beton Pracetak ( 5 kali pakai )

\begin{tabular}{|c|c|c|c|c|}
\hline \multicolumn{5}{|c|}{ Bahan (PERMENPǓPR 28/PRT/M/2016) } \\
\hline Koefisien & $\begin{array}{c}\text { Sa } \\
\mathrm{t}\end{array}$ & Kompenen & Harga & Jumlah Harga \\
\hline 0.008 & $m_{2}^{2}$ & Lantai Keria tebal $10 \mathrm{~cm}$ & $769,000.00$ & $6,152.00$ \\
\hline 9.394 & $\mathrm{~kg}$ & Besi Hollow $(50 \times 50 \times 3) \mathrm{mm}$ & $6,844.80$ & $64,300.07$ \\
\hline 0.005 & $m^{2}$ & Kaso $5 / 7$ & $2,688,000.00$ & $13,440.00$ \\
\hline 0.08 & $\mathrm{Ibr}$ & Phenol film $12 \mathrm{~mm}$ & $210,000.00$ & $16,800.00$ \\
\hline 0.2 & Itto & Minyak Bekisting & $5,500.00$ & $1,100.00$ \\
\hline 3.882 & $\mathrm{bh}$ & Dinabolt Ø $\varnothing 12$ & $2,800.00$ & $10,869.60$ \\
\hline \multicolumn{4}{|l|}{ Total } & $112,661.67$ \\
\hline
\end{tabular}

Upah (PERMENPUPR 28/PRT/M/2016)

\begin{tabular}{|c|c|c|c|c|}
\hline \multicolumn{5}{|c|}{ Upah (PERMENPUPR 28/PRT/M/2016) } \\
\hline Koefisien & $\begin{array}{c}\text { Sa } \\
t\end{array}$ & Komponen & Harga & Jumlah Harga \\
\hline 0.007 & On & Rekeria & $150,000.00$ & $1,050.00$ \\
\hline 0.076 & On & Tukang Kayu & $170,000.00$ & $12,920.00$ \\
\hline 0.008 & On & Kepala Tukang & $190,000.00$ & $1,520.00$ \\
\hline 0.001 & On & Mander & $200,000.00$ & 200.00 \\
\hline \multicolumn{4}{|l|}{ Total } & $15,690.00$ \\
\hline \multicolumn{4}{|c|}{ Total Upah dan Bahan } & $128,351,67$ \\
\hline
\end{tabular}

4. Upah Tuang/Tebar beton 1 bh Komponen untuk Pelat Lantai Pracetak

Tabel 5. Harga Satuan Upah Tuang/Tebar beton 1 bh Komponen

\begin{tabular}{|c|c|c|c|c|}
\hline \multicolumn{5}{|c|}{ Upah (PERMENPUPR 28/PRT/M/2016) } \\
\hline Koefisien & Sat & Komponen. & Harga & Jumlah Harga \\
\hline 0.064 & Oh & Pekeria & $150,000.00$ & $9,600.00$ \\
\hline 0.244 & Oh & Tukang Batu & $170,000.00$ & $41,480.00$ \\
\hline 0.128 & Oh & Tukang Vibrator & $170,000.00$ & $21,760.00$ \\
\hline 0.034 & Oh & Kepala Tukang & $190,000.00$ & $6,460.00$ \\
\hline 0.073 & Oh & Mander & $200,000.00$ & $14,600.00$ \\
\hline \multicolumn{4}{|l|}{ Total } & $93,900.00$ \\
\hline \multicolumn{4}{|c|}{ Total Upah dan Bahan } & $93,900.00$ \\
\hline
\end{tabular}

5. Upah Pemasangan dan Buka Bekisting 1bh Komponen untuk Pelat Pracetak

Tabel 6. Harga Satuan Upah Pemasangan dan Buka Bekisting 1bh Komponen

\begin{tabular}{|c|c|c|c|c|}
\hline \multicolumn{5}{|c|}{ Upah (PERMENPUPR 28/PRT/M/2016) } \\
\hline Koefisien & Sat & Komponen & Harga & Jumlah Harga \\
\hline 0.053 & Oh & Pekeria & $150,000.00$ & $7,950.00$ \\
\hline 0.018 & Oh & Tukang Kayu & $170,000.00$ & $3,060.00$ \\
\hline 0.005 & Oh & Mander & $200,000.00$ & $1,000.00$ \\
\hline \multicolumn{4}{|l|}{ Total } & $12,010.00$ \\
\hline \multicolumn{4}{|c|}{ Total Upah dan Bahan } & $12,010.00$ \\
\hline
\end{tabular}

6. Ereksi 1bh Komponen untuk Pelat Pracetak

Tabel 7. Harga Satuan Ereksi 1bh Komponen untuk Pelat Pracetak

\begin{tabular}{|c|c|c|r|r|}
\hline \multicolumn{2}{|c|}{ Bahan (PERMENPUPR 28/PRT/M/2016) } \\
\hline Koefisien & Sat & Komponen & \multicolumn{1}{c|}{ Harga } & \multicolumn{1}{c|}{ Jumlah Harga } \\
\hline 0.067 & Unit/hc & Sewa Crane & $3,500,000.00$ & $234,500.00$ \\
\hline 6.676 & Itc & Solar & $5,500.00$ & $36,718.00$ \\
\hline 1.1 & Unit/hc & Sewa pipe support & $1,200.00$ & $1,320.00$ \\
\hline Total & & $\mathbf{2 7 2 , 5 3 8 . 0 0}$ \\
\hline
\end{tabular}

\begin{tabular}{|c|c|c|c|c|}
\hline \multicolumn{5}{|c|}{ Upah (PERMENPUPR 28/PRT/M/2016) } \\
\hline Koefisien & Sat & Komponen & Harga & Jumlah Harga \\
\hline 0.067 & Oh & Operator Crane pekeria. & $160,000.00$ & $10,720.00$ \\
\hline 0.067 & Oh & Rembantu Operator crane & $120,000.00$ & $8,040.00$ \\
\hline 0.067 & On & Rekeria & $150,000.00$ & $10,050.00$ \\
\hline 0.067 & Oh & Jukang Batu & $170,000.00$ & $11,390.00$ \\
\hline 0.134 & On & Jukang perakitan & $170,000.00$ & $22,780.00$ \\
\hline 0.067 & Oh & Kepala Tukang & $190,000.00$ & $12,730.00$ \\
\hline 0.067 & Oh & Mander & $200,000.00$ & $13,400.00$ \\
\hline \multicolumn{4}{|l|}{ Total } & $89,110.00$ \\
\hline \multicolumn{4}{|c|}{ Total Upah dan B } & $361,648.00$ \\
\hline
\end{tabular}

7. Topping Pelat Lantai Pracetak Half slab Joint/sambungan pelat lantai pracetak merupakan gabungan dari Analisis beton ready mix dan upah.

Tabel 8. Perhitungan Harga Satuan Topping Pelat Lantai Pracetak

\begin{tabular}{|c|c|c|c|c|}
\hline \multicolumn{5}{|c|}{ Bahan (PERMENPUPR 28/PRT/M/2016) } \\
\hline Koefisien & Sat & Kompenen & Harga & Jumlah Harga \\
\hline 448 & $\mathrm{~kg}$ & Semen Portland & $1,460.00$ & $654,080.00$ \\
\hline 667 & $\mathrm{~kg}$ & Pasir Beton & 230.71 & $153,886.43$ \\
\hline 1000 & $\mathrm{~kg}$ & Kerikil & 100.00 & $100,000.00$ \\
\hline 2100 & Itr & Air & 100.00 & $210,000.00$ \\
\hline \multicolumn{4}{|l|}{ Total } & $1,117,966.43$ \\
\hline
\end{tabular}

\begin{tabular}{|c|c|c|c|c|}
\hline \multicolumn{5}{|c|}{ Upah (PERMENPUPR 28/PRT/M/2016) } \\
\hline Koefisien & Sat & Komponen & Harga & Jumlah Harga \\
\hline 0.367 & $\mathrm{Oh}$ & Tukang Batu & $170,000.00$ & $62,390.00$ \\
\hline 0.074 & Oh & Kenala Tukang & $190,000.00$ & $14,060.00$ \\
\hline 0.037 & $\mathrm{Oh}$ & Mander & $200,000.00$ & $7,400.00$ \\
\hline \multicolumn{4}{|l|}{ Total } & $83,850.00$ \\
\hline \multicolumn{4}{|c|}{ Total Upah dan Bahan } & $1,201,816.43$ \\
\hline
\end{tabular}

\section{Analisis Dasar Harga Satuan Beton Konvensional}

Analisis harga beton konvensional terdiri dari perhitungan pembuatan bekisting pelat lantai di lapangan, pekerjaan pembesian, dan pekerjaan beton.

1. Membuat $1 \mathrm{~m}^{3}$ Beton Fc $37.5 \mathrm{Mpa}$ Slump ( $12 \pm 2$ ) $\mathrm{cm}$

Tabel 9. Perhitungan Membuat $1 \mathrm{~m}^{3}$ Beton Fc $37.5 \mathrm{Mpa}$ Slump ( $12 \pm 2) \mathrm{cm}$

\begin{tabular}{|c|c|c|c|c|}
\hline \multicolumn{5}{|c|}{ Bahan (PERMENPUPR 28/PRT/M/2016) } \\
\hline Koefisien & Sat & Komponen & Harga & Jumlah Harga \\
\hline 1 & $m^{3}$ & $\begin{array}{c}\text { Beton Fc } 37.5 \mathrm{Mpa} \text { Slump } \\
(12 \pm 2) \mathrm{cm}\end{array}$ & $963,000.00$ & $963,000.00$ \\
\hline \multicolumn{4}{|l|}{ Total } & $963,000.00$ \\
\hline
\end{tabular}

\begin{tabular}{|c|c|c|c|c|}
\hline \multicolumn{5}{|c|}{ Upah (PERMENPUPR 28/PRT/M/2016) } \\
\hline Koefisien & Sat & Kempenen & Harga & Jumlah Harga \\
\hline 2.1 & On & Pekeria & $150,000.00$ & $315,000.00$ \\
\hline 0.35 & On & Tukang Batu & $170,000.00$ & $59,500.00$ \\
\hline 0.035 & On & Kepala Jukang & $190,000.00$ & $6,650.00$ \\
\hline 0.105 & On & Mander & $200,000.00$ & $21,000.00$ \\
\hline \multicolumn{4}{|l|}{ Total } & $402,150.00$ \\
\hline \multicolumn{4}{|c|}{ Total Upah dan Bahan } & $1,365,150.00$ \\
\hline
\end{tabular}

\section{Pembesian $1 \mathrm{Kg}$ dengan besi Polos atau Ulir}

Tabel 10. Perhitungan Pembesian $1 \mathrm{Kg}$ dengan besi

Polos atau Ulir

\begin{tabular}{|c|c|c|c|c|}
\hline Bahan (PERMENPUPR 28/PRT/M/2016) \\
\hline Koefisien & Sat & Komponen & Harga & $\begin{array}{c}\text { Jumlah } \\
\text { Harga }\end{array}$ \\
\hline 1.02 & $\mathrm{~kg}$ & Besi Beten & $9,011.00$ & $9,191.22$ \\
\hline 0.05 & $\mathrm{~kg}$ & Kawat beten & $22,500.00$ & $1,125.00$ \\
\hline Total & & $\mathbf{1 0 , 3 1 6 . 2 2}$ \\
\hline
\end{tabular}

\begin{tabular}{|c|c|c|c|c|}
\hline \multicolumn{5}{|c|}{ Upah (PERMENPUPR 28/PRT/M/2016) } \\
\hline Koefisien & Sat & Komponen & Harga & Jumlah \\
\hline 0.025 & On & Rekeria & $150,000.00$ & $3,750.00$ \\
\hline 0.025 & On & Tukang Besi & $170,000.00$ & $4,250.00$ \\
\hline 0.002 & On & Kepala Tukang & $190,000.00$ & 380.00 \\
\hline 0.001 & On & Mander & $200,000.00$ & 200.00 \\
\hline \multicolumn{4}{|l|}{ Total } & $8,580.00$ \\
\hline \multicolumn{4}{|c|}{ Total Upah dan Bahan } & $18,896.22$ \\
\hline
\end{tabular}


3. Pembuatan $1 \mathrm{~m}^{2}$ Bekisting Pelat Lantai

Tabel 11. Perhitungan Pembuatan $1 \mathrm{~m}^{2}$ Bekisting Pelat Lantai

\begin{tabular}{|c|c|c|c|c|}
\hline \multicolumn{5}{|c|}{ Bahan (PERMENPUPR 28/PRT/M/2016) } \\
\hline Koefisien & Sat & Kompenen & Harga & $\begin{array}{l}\text { Jumlah } \\
\text { Harga }\end{array}$ \\
\hline 0.04 & bbr & Kayu Kelas III & $210,000.00$ & $8,400.00$ \\
\hline 0.4 & $\mathrm{~kg}$ & Paku $5 \mathrm{~cm}-12 \mathrm{~cm}$ & $2,948,260.00$ & $1,179,304.00$ \\
\hline 0.2 & Its & Minxak Bekisting & $2,688,000.00$ & $537,600.00$ \\
\hline 0.15 & $m_{n}^{3}$ & Balok Kavu Kelas III & $18,000.00$ & $2,700.00$ \\
\hline 0.35 & Ibro & Plywood tebal 9mm & $5,500.00$ & $1,925.00$ \\
\hline 1 & Bte & $\begin{array}{l}\text { Delken Kayu galam. } \\
\qquad(8-10) \mathrm{cm} \text {, paniang } 4 \mathrm{~m}\end{array}$ & $7,530.00$ & $7,530.00$ \\
\hline \multicolumn{4}{|l|}{ Total } & $1,737,459.00$ \\
\hline
\end{tabular}

\begin{tabular}{|c|c|c|c|c|}
\hline \multicolumn{5}{|c|}{ Upah (PERMENPUPR 28/PRT/M/2016) } \\
\hline Koefisien & Sat & Komponen & Harga & $\begin{array}{l}\text { Jumlah } \\
\text { Harga }\end{array}$ \\
\hline 0.66 & On & Rekeria & $150,000.00$ & $99,000.00$ \\
\hline 0.03 & On & Jukang Kavu & $170,000.00$ & $5,100.00$ \\
\hline 0.033 & Oh & Kepala Tukang & $190,000.00$ & $6,270.00$ \\
\hline 0.033 & On & Mander & $200,000.00$ & $6,600.00$ \\
\hline \multicolumn{4}{|l|}{ Total } & $116,970.00$ \\
\hline \multicolumn{4}{|c|}{ Total Upah dan Bahan } & $1,854,429.00$ \\
\hline
\end{tabular}

\section{Pembahasan Hasil Analisis Kebutuhan Biaya}

Berikut ini adalah tabel hasil analisis kebutuhan biaya yang di hitung untuk pekerjaan pelat lantai dermaga 006 pelabuhan tanjung priok dengan metode Pracetak dan metode konvensional.

Tabel 12. Perhitungan Pembahasan Hasil Analisis Kebutuhan Biaya

\begin{tabular}{|l|c|r|r|c|}
\hline \multicolumn{1}{|l|}{ Rekapitulasi 1 Komponen Beton Konvensional } \\
\hline Macam pekeriaan & Satuan & Koefisien & $\begin{array}{c}\text { Harga bahan } \\
\text { \& Upah }\end{array}$ & Total \\
\hline Beten Plat lantai Dermaga & $\mathrm{m}_{2}^{3}$ & 9.646875 & $1,365,150.00$ & $13,169,431.41$ \\
\hline Besi Tulangan & $\mathrm{kg}$ & 1447.03125 & $18,896.22$ & $27,343,420.85$ \\
\hline Bekisting & $\mathrm{m}^{2}$ & 30.31875 & $357,020.40$ & $10,824,412.25$ \\
\hline Total & & $\mathbf{5 1 , 3 3 7 , 2 6 4 . 5 1}$ \\
\hline
\end{tabular}

\begin{tabular}{|c|c|c|c|c|}
\hline \multicolumn{5}{|c|}{ Rekapitulasi 1 Komponen Beton Pracetak } \\
\hline Macam pekeriaan & Satuan & Koefisien & $\begin{array}{c}\text { Harga bahan } \\
\text { \& Unah }\end{array}$ & Total \\
\hline Beton & $m^{3}$ & 4.8234375 & $1,520,116.43$ & $7,332,186.59$ \\
\hline Upah Tuang & $m^{3}$ & 9.646875 & $93,900.00$ & $905,841.56$ \\
\hline Besi Tulangan & $\mathrm{kg}$ & 1447.03125 & $12,252.05$ & $17,729,099.23$ \\
\hline Bekisting & $m^{2}$ & 30.31875 & $128,351,67$ & $3,891,462.29$ \\
\hline Buka Bekisting & bh & 1 & $12,010.00$ & $12,010.00$ \\
\hline Ereksilinstal lantai pracetak & $\mathrm{Bh}$ & 1 & $361,648.00$ & $361,648.00$ \\
\hline Topping Relat Pracetak ( 1 bh precast) & $\mathrm{Bn}$ & 4.8234375 & $1,201,816.43$ & $5,796,886.43$ \\
\hline \multicolumn{4}{|l|}{ Total } & $36,029,134.10$ \\
\hline
\end{tabular}

\section{Analisis Waktu Pekerjaan Pelat Lantai Beton Konvensional}

Schedule pelaksanaan terhadap pekerjaan pelat lantai beton konvensional adalah selama bulan waktu yang di rencanakan. Pada penggunaan Pracetak diharapkan dapat mereduksi dari segi waktu pelaksanaan pekerjaan pelat lantai beton dari schedule yang direncanakan sehingga dapat deviasinya terhadap pekerjaan tersebut. Pada tabel 13 di bawah ini adalah schedule rencana dari waktu pekerjaan pelat lantai beton konvensional pada proyek dermaga 006 pelabuhan tanjung priuk.

Tabel 13. Perhitungan Waktu Pekerjaan Pelat Lantai Konvensional

\begin{tabular}{|c|c|c|c|c|c|c|c|c|c|c|c|c|}
\hline \multicolumn{13}{|c|}{ Tahun 2018} \\
\hline & \multicolumn{4}{|c|}{ Mei } & \multicolumn{4}{|c|}{ Juni } & \multicolumn{4}{|c|}{ Juli } \\
\hline Area & M.1 & M.2 & M.3 & M.4 & M.1 & M.2 & M.3 & M.4 & M.1 & M.2 & M.3 & M.4 \\
\hline Konvensional & & & & & & & & & & & & \\
\hline Dermaga 006 & & & & & & & & & & & & $=$ \\
\hline & & & & & & & & & & & & \\
\hline
\end{tabular}

\section{Siklus Produksi Pelat Lantai Pracetak Half slab}

Untuk memudahkan pekerjaan produksi sampai instalasi di lapangan maka dibuat jam kerja berdasarkan jenis pekerjaan tunjuannya adalah agar pelaksanaan pekerjaan yang dilakukan dengan Pracetak berjalan lancar sesuai dengan rencana schedule pelaksanaan pekerjaan di proyek dan untuk menghindari keterlambatan dalam produksi dan instalasi, seperti pada tabel di bawah ini

Tabel 14. Perhitungan Siklus Produksi Pelat Lantai Pracetak

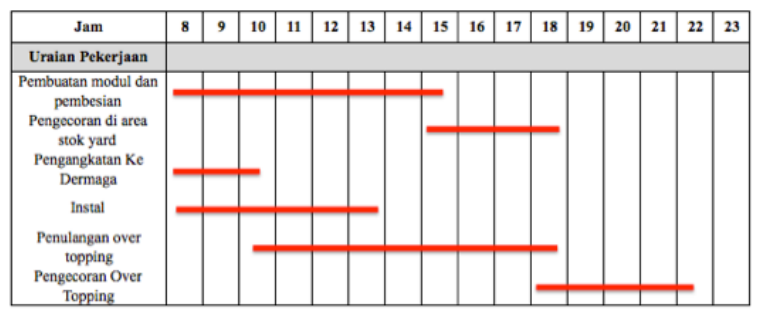

Target Produksi Pelat Lantai Pracetak Half slab

Untuk menyesuaikan dengan schedule pelaksanaan pekerjaan pelat lantai,maka dari itu dibuat target produksi jika dengan metode Pracetak berapa yang dapat dihasilkan dan juga kemampuan terhadap pekerjaan installnya, oleh dari itu penulis mencoba membuat berdasarkan dari Analisis kemampuan perminggu yang dihasilkan dengan cara metode Pracetak lalu setelah didapat direncanakan berapa jumlah waktu yang dibutuhkan untuk keseluruhan pekerjaan pemasangan,seperti tabel dibawah ini.

Tabel 15. Perhitungan Siklus Produksi Pelat Lantai Pracetak Half slab

\begin{tabular}{|c|c|c|c|c|c|c|c|c|c|c|c|}
\hline No & Uraian & Jam & H1 & H2 & H3 & H4 & H5 & H6 & H7 & Jml & Sat \\
\hline 1 & $\begin{array}{c}\text { Pembuatan modul } \\
\text { dan pembessian }\end{array}$ & $\mathbf{0 8 . 0 0 - 1 5 . 0 0}$ & 4 & 4 & 4 & 4 & 4 & 4 & & 24 & Pcs \\
\hline 2 & $\begin{array}{c}\text { Pengecoran di area } \\
\text { stok yard }\end{array}$ & $\mathbf{1 5 . 0 0 - 1 8 . 0 0}$ & 4 & 4 & 4 & 4 & 4 & 4 & & 24 & Pcs \\
\hline 3 & $\begin{array}{c}\text { Pengangkatan Ke } \\
\text { Dermaga }\end{array}$ & $\mathbf{0 8 . 0 0 - 1 0 . 0 0}$ & & 3 & 4 & 4 & 4 & 4 & 4 & 23 & Pcs \\
\hline 4 & lostal & $\mathbf{0 8 . 0 0 - 1 3 . 0 0}$ & & 3 & 4 & 4 & 4 & 4 & 4 & 23 & Pcs \\
\hline 5 & $\begin{array}{c}\text { Penulangan Over } \\
\text { Topping }\end{array}$ & $\mathbf{1 0 . 0 0 - 1 8 . 0 0}$ & & 3 & 3 & 3 & 3 & 3 & 3 & 18 & Pcs \\
\hline 6 & $\begin{array}{c}\text { Pengecoran Over } \\
\text { Topping }\end{array}$ & $\mathbf{1 8 . 0 0 - 2 2 . 0 0}$ & & 3 & 3 & 3 & 3 & 3 & 3 & 18 & Pcs \\
\hline
\end{tabular}

Dari Analisis yang didapat volume produksi pelat lantai Pracetak per minggu untuk Pracetak sebanyak 24 pcs dan kemampuan instal 23 pcs. Setelah itu dapat diketahui dalam waktu satu bulan kemampuan untuk produksi dapat menghasilkan sebanyak 90 pcs dan untuk instal sebanyak 90 pcs. Angka ini didapat dari : produksi satu bulan (24pcs $\times 4$ minggu $=90$ pcs), instal satu bulan ( 23 pcs $\times 4$ minggu $=90$ pcs $)$. Dari total Pracetak yang ada : 90 pcs. Maka waktu yang dibutuhkan untuk produksi dan waktu yang dibutuhkan untuk pemasangan dapat langsung diketahui, 1 bulan untuk produksi dan instal Pracetak half slab dan 1,25 bulan untuk pekerjaan pengecoran over topping. Angka ini didapat dari total angka produksi Pracetak dibagi dengan produksi per minggu nya : produksi ( 90 pcs : 23 pcs = 3.91 minggu), sedangkan over topping total Pracetak dibagi dengan kemampuan pengecoran over 
topping per minggu nya ( 90 pcs : 18 pcs = 5 minggu) seperti yang terlihat pada tabel di bawah ini.

Tabel 16. Volume Total Produksi Pelat Lantai Pracetak Half slab

\begin{tabular}{|l|c|c|}
\hline \multicolumn{1}{|c|}{ Keterangan } & Qty & Satuan \\
\hline Total Pracetak & 90 & Pcs \\
\hline Kapasitas Produksi(install)/minggu & 23 & Pcs \\
\hline Kapasitas Over Topping/ minggu & 18 & Pcs \\
\hline Waktu yang di butubkan untuk keseluruhan produksi & 3.91 & Minggu \\
\hline Waktu yang di butubkan untuk keseluruhan pemasangan & 5 & Minggu \\
\hline
\end{tabular}

Analisa yang didapat Produksi Pelat Lantai Pracetak Half slab dan Konvensional

Berdasarkan Analisis yang didapat untuk pekerjaan pelat lantai Pracetak half slab untuk proyek dermaga 006 pelabuhan tanjung priuk bahwa metode Pracetak half slab lebih menguntungkan dari segi waktu pelaksanaan seperti yang terlihat dalam tabel di bawah ini.

Tabel 17. Pembahasan Hasil Analisis Waktu Metode Pracetak dan Konvensional

\begin{tabular}{|c|c|c|c|c|c|c|c|c|c|c|c|c|}
\hline \multirow{3}{*}{ Keterangan } & \multicolumn{12}{|c|}{ Tahun 2018} \\
\hline & \multicolumn{4}{|c|}{ Mei } & \multicolumn{4}{|c|}{ Juni } & \multicolumn{4}{|c|}{ Juli } \\
\hline & M.1 & M.2 & M.3 & M.4 & M.1 & M.2. & M.3 & M.4 & M.1. & M. 2. & & \begin{tabular}{l|l}
$3 . \mathbf{M . 4}$ \\
\end{tabular} \\
\hline & & & & & & & & & & & & \\
\hline \multicolumn{13}{|l|}{ Konvensional } \\
\hline \multicolumn{13}{|l|}{ Pengecoran Pelat Lantai Konvensional } \\
\hline \multicolumn{13}{|l|}{ Precast Half Slab } \\
\hline Pekerjaan Instal Half Slab & & & & & & & & & & & & \\
\hline Pekerjaan Pengecoran Over Topping & = & & $=$ & & ․ & & & & & & & \\
\hline & & & & & & & & & & & & \\
\hline
\end{tabular}

\section{KESIMPULAN}

1. Dari hasil Analisis yang didapat untuk pekerjaan pelat lantai dermaga 006 pelabuhan tanjung priok dengan metode beton konvensional dan beton Pracetak. Metode pracetak didapat penghematan sebesar 29.82\% atau 15,308,130.41 jika dibandingkan dengan metode beton konvensional. Ini karenakan pemakaian bekisting yang bisa dipakai 5 kali.

Tabel 18. Pembahasan Hasil Analisis Biaya Metode

Pracetak dan Konvensional

\begin{tabular}{|l|lr|lr|}
\hline \multicolumn{1}{|c|}{ Item } & \multicolumn{2}{c|}{ Beton Konvensional } & \multicolumn{2}{c|}{ Precast Half Slab } \\
\hline Biaya & Rp. & $51,337,264.51$ & Rp. & $36,029,134.10$ \\
\hline Selisih & Rp. & \multicolumn{3}{|c}{} \\
\hline Presentase & \multicolumn{2}{|c|}{$\mathbf{2 9 . 8 2 \%}$,308,130.41 } \\
\hline
\end{tabular}

2. Untuk waktu pelaksanaan pekerjaan pelat lantai dermaga 006 pelabuhan tanjung priuk dengan metode beton pracetak half slab dapat menghemat waktu 7 minggu dari metode konvensional. Ini dikarenakan antar pekerjaan install dan pengecoran topping sistem beton precast dapat dikerjakan dalam waktu bersamaan karena lokasi pekerjaan berbeda. Beda hal nya dengan sistem beton konvensional yang harus menunggu beberapa pekerjaan seperti bekisting, pembesian setelah itu dilakukan pengecoran. Metode ini sangat membantu kontraktor dalam menghemat waktu pekerjaan
Tabel 19. Pembahasan Hasil Analisis Waktu Metode Pracetak dan Konvensional

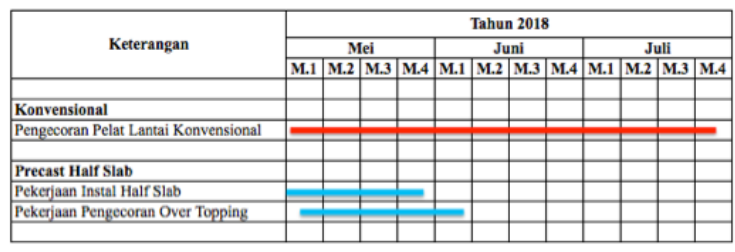

\section{SARAN}

Dengan menggunakan metode beton pracetak half slab pada pekerjaan pelat lantai dermaga 006 pelabuhan tanjung priuk diharapkan menjadi rekomendasi pemilihan metode pekerjaan, yang dimana penggunaan nya dapat mereduksi biaya dan waktu, serta dapat meminimalisir kesalahan pada pelaksanaannya karena pengawasannya yang dilakukan secara langsung oleh kontraktor.

\section{REFERENSI}

Badan Standar Nasional. (2012). Tata Cara Perancangan Beton Pracetak dan Beton Prategang untuk Bangunan Gedung SNI7833- 2012. Jakarta: Badan Standar Nasional.

Badan Standar Nasional. (2013). Persyaratan Beton Struktural untuk Bangunan Gedung SNI- 2847-2013. Jakarta: Badan Standar Nasional.

Tata Cara Perhitungan Harga Satuan Pekerjaan Bidang Pekerjaan Umum PERMENPUPR 28/PRT/M/2016.

PCl Industry Handbook Committe. (2004). PC! Design Handbook Precast and Prestressed Concrete, Sixth Edition. Chicago: Precast/Prestressed Concrete Institue.

Wulfram I. Ervianto. (2006.) Ekplorasi Teknologi dalam Proyek Konstruksi Beton Pracetak dan Bekisting. Yogyakarta: Penerbit Andi Offset. 